\title{
Tricuspid Valve Regurgitation Velocity
}

National Cancer Institute

\section{Source}

National Cancer Institute. Tricuspid Valve Regurgitation Velocity. NCI Thesaurus. Code C136979.

A measurement of the backward flow of blood through the tricuspid valve during right ventricle contraction. It correlates with pulmonary artery systolic pressure at rest and with exercise. A tricuspid regurgitation velocity greater than or equal to $2.5 \mathrm{~m} / \mathrm{sec}$ on echocardiog raphy is a surrog ate marker for pulmonary hypertension in adults with sickle cell disease. 